\title{
Managing the uncertainty in time scheduling of public construction works in Greece
}

\section{Dimitrios Giannoulis}

Department of Construction Works, Regional Unit of Zakynthos, Region of Ionian Islands, Dioikitirio, Zakynthos GR-29100, Greece

Email: d_giannoulis@yahoo.gr

\section{Konstantinos Salonitis*}

Manufacturing and Materials Department,

Cranfield University,

Cranfield MK43 0AL, UK

Email: k.salonitis@cranfield.ac.uk

${ }^{*}$ Corresponding author

\begin{abstract}
The construction of public works in Greece usually faces in practice significant deviations from its time scheduling. The aim of this paper is to study and evaluate the possibilities of managing these uncertainties by applying a probabilistic approach mainly based on the method of Monte Carlo simulation. State-of-the-art software was used allowing a better integration of different sources of uncertainty into the time scheduling. The software was applied in an already constructed work and the results were compared with real recorded data. The application demonstrated the strong performance of the Monte Carlo Method and its ability to deal efficiently with uncertainty. The divergence between the results of the Monte Carlo Method and the real data disclosed some structural weaknesses of the ruling framework of public works in Greece that extent the uncertainties. Finally, suggestions are discussed for institutional changes that will assist in a more efficient and accurate time scheduling of the Greek public works.
\end{abstract}

Keywords: public works; uncertainty; Monte Carlo method; time scheduling.

Reference to this paper should be made as follows: Giannoulis, D. and Salonitis, K. (2015) 'Managing the uncertainty in time scheduling of public construction works in Greece', Int. J. Collaborative Enterprise, Vol. 5, Nos. $1 / 2$, pp.58-73.

Biographical notes: Dimitrios Giannoulis is a Mechanical Engineer graduated from the University of Patras, Greece, with a Diploma in Mechanical Engineering in 1998. He holds a Diploma in Environmental \& Applied Fluid Dynamics from von Karman Institute for Fluid Dynamics, Belgium, in 1999 and an MSc on Engineering Project Management from the Hellenic Open University. He is the Director of the Construction Works Department at the Regional Unit of Zakynthos at the region of Ionian Islands. 
Konstantinos Salonitis is a Lecturer in Manufacturing Systems in Cranfield University. He graduated from the University of a Patras with a Diploma in Mechanical Engineering in 2001 and was awarded a $\mathrm{PhD}$ on Manufacturing Processes in 2006. He has worked as a Research Engineer at the University of Patras in a number of research projects funded by the CEU. He has participated in more than 10 projects as Project Manager or Technical Site Manager. He joined Cranfield University in February 2012; he is the Manufacturing and Management Program Director. He has published more than 130 research papers in major international journals and internationally referred conferences.

\section{Introduction}

Technical projects encounter, by their nature, increased uncertainties concerning time scheduling and completion within deadline. Majid and McCaffer (1998) discussed the factors that contribute to such delays and grouped them in three major classifications: the ones caused by the client, the ones caused by the contractors and finally the ones that are due to 'acts of God' and/or a third party. Out of these three classifications, only the latter can be considered as 'excusable' delays. Odeh and Battaineh (2002), categorised the causes of delays into eight major groups, namely client related factors, contractor related factors, consultant related factors, material factors, labour and equipment factors, contract factors, contractual relationships and finally external factors.

In the case of public construction works in Greece, the uncertainties that lead to delays seem to be even higher for a number of reasons such as the complicated legislation, the wide spread of control and approve stakeholders and the financial recession of the last years. A better management of uncertainty will reduce time delays in project completion, will assist in better management of resources and ultimately will lead to more cost-effective and in time completed projects. This is crucial because it will increase the economical efficiency of the public construction work and optimise its impact in the growth of national economy. In the literature, a number of attempts have been documented for increasing the confidence in the predictions of both the duration and the cost of construction projects. Indicatively, Kaleem et al. (2014) developed mathematical models for predicting the construction duration of a highway project based on multivariate regression analysis correlation of the time overrun with potential risk factors from the planning phase. A number of studies focus in assessing historical data in order to identify trends and patterns related to the delays of construction projects (Anastasopoulos et al., 2012). Alternatively, fuzzy logic approaches have been developed and suggested for a number of different projects within different geographical contexts such as Turkey (Gunduz et al., 2013) and Greece (Chrysafis and Papadopoulos, 2014; Maravas et al., 2012). Construction delay analysis techniques (Braimah, 2013) can be also used for improving the reliability of the duration predictions.

The purpose of this paper is to study and evaluate the possibilities of managing successfully the uncertainty of public construction works in Greece applying existing methods of time scheduling. The examination of some possible modifications and proper parameterisations of the methods aims to a more precise adjustment to the actual terms and conditions of the construction. Thus, the management of uncertainty is feasible in practice and finally a more reliable time scheduling possible. 
Dealing with uncertainty makes it necessary to overcome the deterministic methods of time scheduling (critical path method, etc.) and focus on the probabilistic ones. The program evaluation and review technique (PERT) is the first and most widely spread technique to deal with projects under uncertainty. It relies on basic stochastic analysis approach assuming each activity's duration as a stochastic variable and proposes an approximation method to calculate the cumulative time of the project and its variance. Since its introduction (Malcolm et al., 1959) PERT has been object of wide research work, which delivered numerous variants of the original method with improvement features (Adlakha, 1989; Trietsch and Baker, 2012). However, in the current study, the standard PERT method is applied by offering a first reference of probabilistic analysis. The core work is based on Monte Carlo method (MCM), which in fact performs a simulation of the project schedule in order to deliver a probability distribution of the overall project time duration. This result quantifies the project risks and uncertainties and improves the confidence to the time scheduling. The MCM can be easily completed by using standard project management software such as Microsoft Project or Primavera along with Monte Carlo simulation add-ins.

The time scheduling has not been widely studied in Greek construction works. Only few university theses have been documented employing both deterministic and probabilistic methods (Tzintzas, 2005; Chatzinikolaou, 2005; Tsagkos, 2009). This is the first effort of applying a state-of-the-art Monte Carlo Simulation in order to manage the uncertainties of time scheduling in construction works in Greece and especially in those of public sector. Conclusively, the aim of this study is to validate the possibilities of managing the uncertainty by applying advance scheduling methods of MCM and taking advantage of its entire features for specialised modelling.

Although the results drawn indicated significant differences; the added value of MCM in managing the uncertainty is strongly demonstrated. By explaining these differences a series of systematic factors that influence the time scheduling are highlighted and are mainly related with the legal framework and other institutional weaknesses of the Greek system for construction public works.

\section{Public construction works in Greece}

Public construction works refer to the development of infrastructure, and thus based on the Organization for Economic Co-operation and Development (OECD) definition this includes roads, utility lines and public buildings. Public construction works accounted for $1.2 \%$ of Greek gross domestic product (GDP) in 2012, dropping from 3.6\% in 2006 as a result of the economic crisis (PWC, 2014). As a reference it can be noted that in a worldwide level, the investment in public constructions is $3.6 \%$ of GDP, whereas for Europe this is $\sim 2 \%$. In general, however, the public construction works sector in Greece is a strong one, and for each euro spent on infrastructure, the GDP is further increased by two Euros (economic multiplier of around $2 \mathrm{x}$ ). Nevertheless, the forecast for the future is better (Figure 1), and the total value of programmed construction works until 2022 is approximately $€ 20.1$ billion.

Funding of public construction works in Greece is based on one of the three following funding bodies. Public sector (i.e., the government (state) and the European commission) funds $\sim 40 \%$ of the total infrastructure investments. Banking sector (European Investment 
Bank and other banks) provide loans for $\sim 45-50 \%$ of the investments. Finally, public-private partnerships (PPP) fund the remaining $15 \%$ of the total projects' budget (PWC, 2014).

Figure 1 Forecast of public construction works to be completed in Greece (see online version for colours)

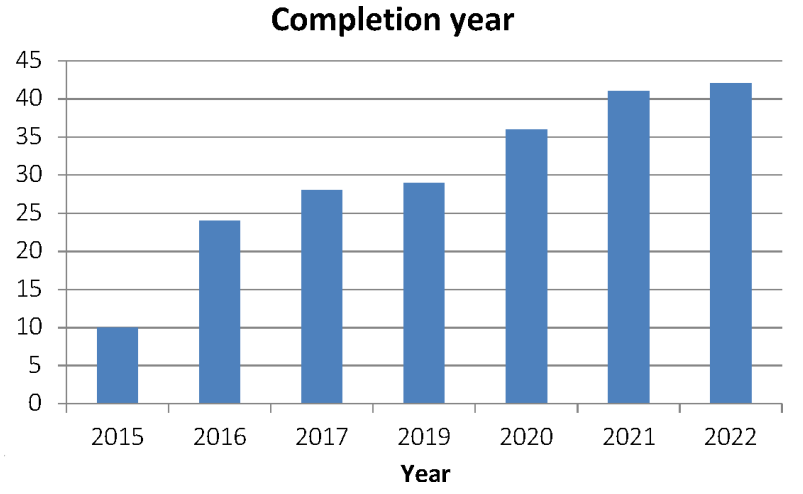

Source: Based on data presented in PWC (2014)

\section{Proposed method}

The method followed in this paper is the application of MCM in an already constructed public work in order to evaluate its performance and reliability in managing the uncertainty in times scheduling. The evaluation is based on the comparison of the computational results with real data. Furthermore, computation performed also with the classical PERT is used as an additional benchmark to validate the performance of the utilised MCM

\subsection{PERT method}

PERT is the primary tool for time scheduling in project management based on probabilistic approach. It models each activity as a stochastic variable with the underlying assumption that time duration is beta distributed. Traditional PERT proposes an approximation method to calculate the mean and the variance of the activity duration. In fact, it proposes the use of three duration estimates for each activity (the optimistic $T_{o}$, the most likely $T_{m}$ and the pessimistic estimate $T_{p}$ ) to approximate the mean $T_{e}$ and the variance $\sigma_{e}$ of the beta probability density function, as shown in Figure 2. According to the classical PERT, these figures are estimated as:

$$
\begin{aligned}
& T_{e}=\frac{T_{o}+4 \cdot T_{m}+T_{p}}{6} \\
& \sigma_{e}=\frac{T_{p}-T_{o}}{6} .
\end{aligned}
$$

A literature review shows numerous other assumptions to be proposed for the type of the probability density function and the formulas to approximate the mean and the variance 
(Golenko-Ginzburg, 1989). For example Hajdu and Bokor (2014) compared the PERT results for different distributions types (beta, triangular and uniform) and concluded that the type of distribution has a strong impact on the results. However, the classical PERT is preferable as an adequate approach for the profile of the examined case.

Figure 2 Typical density function of the PERT-beta distribution (see online version for colours)

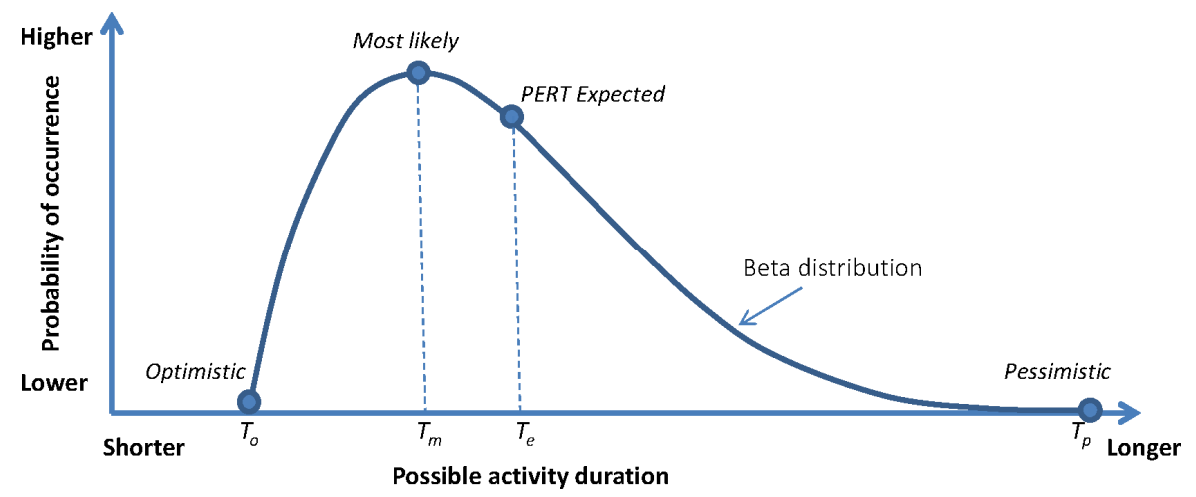

\subsection{Monte Carlo method (MCM)}

The backbone of the current analysis is the simulation of MCM. The method assumes a computational algorithm that is triggered by a repeated random sampling to obtain numerical results. In practice, the algorithm relies on the critical path method (CPM) calculations for the specific project. For each task in the project network a probability distribution faction is assigned. A three-point estimate (the optimistic $T_{o}$, the most likely $T_{m}$ and the pessimistic estimate $T_{p}$ ) is often used to customise the probability function. Random sampling assigns numerical values for the duration of each activity in any simulation. Running the simulation for many times we obtain the distribution of the overall time of the project.

The MCM is offered nowadays in software packages with many new features that allow better modelling of time scheduling with integration of different sources of uncertainty in the estimations and consequently the expectation of more accurate and reliable results.

The modern programs support different types of probability distributions facilitating a more realistic approach to the real duration of each individual task of the project. The most appropriate type can be selected for every case while the definition of the distribution is based on the three-point estimation mentioned above. Furthermore, it is offered the possibility to define index such as confidence interval (CI) that measure the confidence in the three-point estimation (for example a CI $90 \%$, means an expectation $90 \%$ of possible duration to fall between the optimistic and pessimistic value). Another aspect of such computational packages is the ability to specify correlations for the durations of various tasks with outside factors (for example weather, subcontractors, etc.). This is achieved by introducing parameters such as correlation coefficient (CC) that measures the degree of interdependence in terms of a percentage between $-100 \%$ and $100 \%$ (for positive or negative correlation, respectively).

The software packages perform the Monte Carlo simulation delivering the results in different types of histograms and charts. The most important of them is the project finish 
histogram displaying the early finish of the whole project (or other target is selected). In addition, they offer the possibility for sensitivity analysis based on indexes such as the sensitivity index (SI) and the sensitivity attributable variance (SAV). The SI defined as the percentage of time the task is critical, multiplied by the standard deviation of its duration and divided by the standard deviation of the finish date of the sensitivity target. And the SAV of task, defined as the square of the correlation between the task duration and the finish date of the sensitivity target expressed as a percentage. Furthermore, it can be investigated the effect of the correlation sources, separately or in various combinations, and delivering estimations of the sensitivity of the project finish date to each of the correlation sources.

In this paper, the software package that used was Full Monte ${ }^{\circledR}$ of Barbecana Inc. (Barbecana Inc., 2012). This is an add-in for project management software program Microsoft Project ${ }^{\circledR}$ with improved features.

\section{The productivity rate estimation problem}

One of the most critical issues of time scheduling is to determine effectively the duration of each individual task. This seems to be the first and one of the major sources of uncertainty. The accurate prediction of the duration of an activity is researched a lot, and a number of different factors have an impact on the performance of constructor. For example, Xiao and Proverbs (2002) compared contractors from different countries with regards the construction time performance, indicating great differences related to the practices followed in different countries.

The time duration of a task can be either a matter of calculation or empirical estimation. Although the first approach is preferable since it is more reliable, in practice the second one is almost the standard practice in Greek public construction reality. This is not only because empirical estimation is obviously less demanding in sources and time effective. The main issue is the lack of a reliable and contemporary database of productivity rates for the different constructive tasks of the technical works in Greece. Although such databases are available from many sources internationally, they are not considered effective enough for the Greek case or for any country in general. This is due to the fact that technical methods, practices and standards usually differ from country to country following the particular technical culture, the available materials and the climatic and geographical requirements.

A literature review of Greek bibliography revealed only a few sources of technical data about the productivity rates of various technical tasks. These sources cannot be considered as real databases but they can provide directly data for the productivity rates. Such sources are the "Analytical papers of pricing public works" issued by the Greek ministry responsible for the public works and the 'Tables of IKA' (National Insurance Institute) for calculating the number of labour days which are required per unit of construction work. For this case, the first one is called for simplicity reasons 'Tottee Method' and the second one 'IKA method'.

\subsection{The 'Tottee method'}

The analytical papers have been used for decades for pricing the public works in Greece. They contain an analytical calculation for the unit cost of any technical work based 
on the demanding quantity of materials and the amount of labour work needed. Thus, the productivity rate can be predicted in terms of time per unit of produced work. Since the corresponding quantity of the work has been estimated by the work-study, the estimated duration is calculated by multiplying the productivity rate by the total amount of the work. This procedure is followed for all the individual works. However, the time scheduling is referred in activities-tasks, which in fact consist of relevant individual works. The estimated duration of every activity is the sum of the estimated durations of this relevant works.

The main advantage of this method is its independence from any subjective empirical estimation. The major drawback, the analytical papers of pricing public works are quite obsolete. They were introduced in the 1960s and not one revised edition has been published since then. Consequently, they do not cover modern constructive works and furthermore they refer to old fashioned productivity methods and techniques. Thus, the contained productivity rates are very conservative, leading to underestimation of the task duration.

\subsection{The 'IKA method'}

This method is based on Tables issued by 'IKA' (the 'National Insurance Institute' in Greece) in order to offer an objective calculation of the required insurance contributions of the employees to a technical work. The 'Tables of IKA' contain productivity rates in terms of required labour days per unit of construction work. In this paper, it is proposed to use them so as to calculate the duration of each individual work by multiplying the relevant productivity rate by the total amount of the work as estimated in the work-study. Once again, the duration of every activity of the time scheduling will be calculated as the sum of the durations of the relevant works. The 'Tables of IKA' were introduced in 2002 and therefore the productivity rates rely on the current construction methods and techniques and seem to be more realistic.

The main problem with the 'Tables of IKA' is that are referred only to building construction works. Thus, 'IKA method' cannot be used for another type of public works, such as road works, hydraulic works, etc. This is a major drawback since it is not applicable to the great mass of the public works.

\subsection{The experts'suggestion}

Instead of analytical calculation, an expert can estimate the expected duration of each individual task. A person with previous relevant experience in project management can effectively assume the probable duration of each task. Although this method seems to be very subjective, it can deliver reliable results and overtake weak points of the analytical calculation. Its main advantage is that it takes into account the local specific conditions, such as the availability of skilled workforce, the supply of materials, special issues of health and safety, the weather and geographical parameters, etc. All these factors cannot be expressed in an analytical calculation. Therefore, it deals better with the managing of uncertainty since it directly integrates into estimations such sources. On the other hand, owing to the subjectively of the estimation, the bias or the personal preferences of the expert consist a considerable disadvantage. This can be treated by using more than one expert and taking the average suggestion, or by using a different expert for each task or doing both. Another disadvantage is that it is time-consuming. Although it would be 
expected to be rapid in its application, in fact it takes more time than the analytical calculation. A reliable estimation demands a detailed study of all the technical data, a market research for materials and manpower and probably an onsite inspection.

The proposed approach thus for predicting the duration of a public construction work is shown graphically in Figure 3, starting with the formulation of the work break down structure (WPS) resulting in the estimated duration of the whole project with a CI.

Figure 3 Approach for estimating project duration within Greek public works context (see online version for colours)

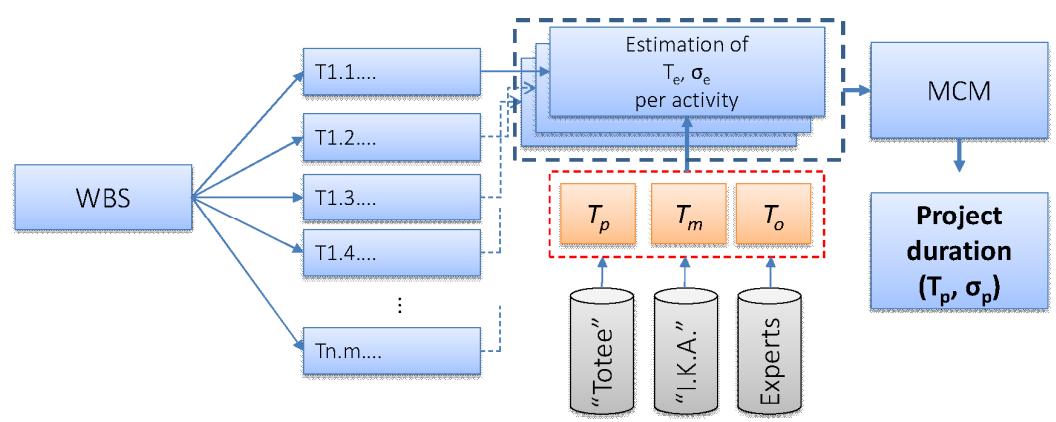

\section{Test case: construction of a school building: the project}

The test case refers to the construction of a primary public school, in the island of Zakynthos, in Greece. The '3rd Primary School of Riza' (Figures 4 and 5) is located $12 \mathrm{~km}$ from the capital city of Zakythos and the complex of $1.284,43 \mathrm{~m}^{2}$ of buildings and $4.026,83 \mathrm{~m}^{2}$ of forecourt offers all the necessary facilities according to the standards of the Greek Ministry of Education.

Figure 4 3rd primary school of Riza
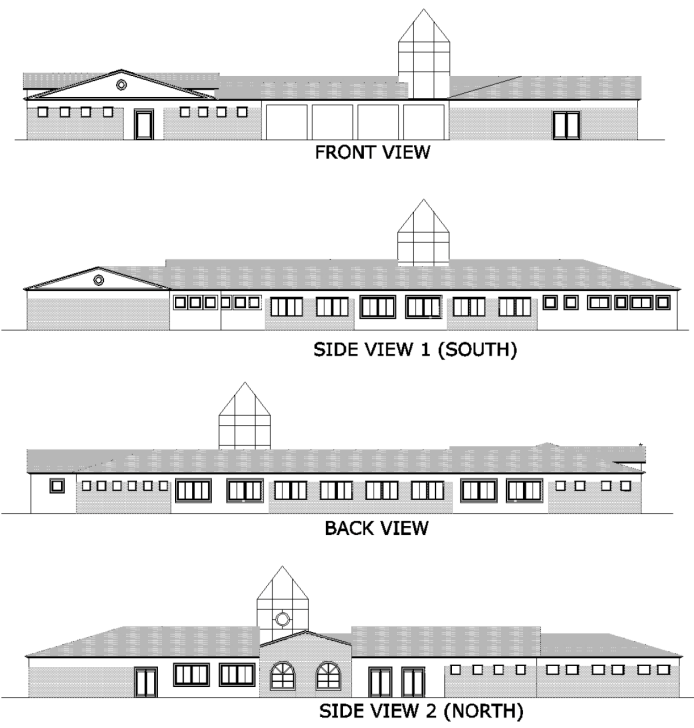
Figure 5 Satellite picture of 3rd primary school of Riza (Google Earth, $37^{\circ}, 48^{\prime}, 58.23^{\prime \prime} \mathrm{N}$, $20^{\circ}, 47^{\prime}, 17.54^{\prime \prime} \mathrm{E}$ ) (see online version for colours)

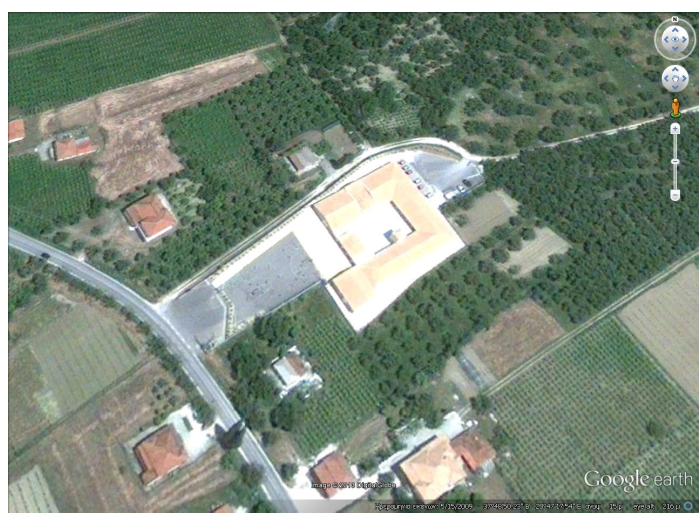

The work was co-funded by the European Union and the Greek government under the 3rd Community Structural Fund 2000-2006. Its initial budget was 1.913.120,00€ and auctioned in 8 September, 2005. The underbid contractor offered a discount of $6985 \%$. The construction contract was signed at 27 October, 2005 for a total cost of $€ 1,779,483.98$ and pre-estimated duration of 660 days. The project finally was completed in 12/10/2007 and its duration lasted 715 days.

\section{Method implementation}

The implementation of time scheduling premises the project structural analysis by following the work breakdown structure (WBS) method. Throughout this procedure the case project decomposed finally into 34 individual distinct tasks (activities) and determined the logical proceeding relationships between them (as can be seen if Figure 3).

Furthermore, in each task assigned its estimated time duration. This was based on the three proposed techniques mentioned above in Sections 4.1-4.3. In the case of CPM, 'the expert's suggestion' estimate was chosen for the time durations as the most appropriate.

In the case of PERT and MCM, the three durations estimate is necessary. Thus, the three techniques are applied by assigning the 'IKA method' to the optimistic duration estimate $T_{o}$, the 'expert's suggestion' to the most likely $T_{m}$ and 'Totee method' to the pessimistic estimate $T_{p}$. The proposed assignment comes out through the pros and the cons of each technique as it is explained in Sections 4.1-4.3.

The time scheduling of the case project performed on the MS Project ${ }^{\circledR}$, equipped with the 'Project PERT Add-in' and 'Full Monte ${ }^{\circledR}$, add-in software program for the PERT and MCM calculations, respectively. The MS Project properties are set up according to the real situations of the case project. In the PERT calculations the levels of importance defined as 1 for Optimistic, 4 for Expected and 1 for Pessimistic. In the main scenario of MCM calculation the Beta-type distribution was chosen for the duration of each individual task, while the CI assumed $99 \%$ and ignored any potential correlation with external sources. 
One of the key decisions in the MCM analysis that needs to be made is the number of simulations to be undertaken. Higher number of simulations increases the accuracy of the results and thus the confidence that someone can have in them. However, increasing too much the number of simulations, results in higher computational effort, nevertheless this is not a problem nowadays due to higher capacity and capability of modern personal computers. The required number of simulations can be estimated taking into consideration the standard error of mean (SEM), using the following equation:

$$
\mathrm{SEM}=\frac{\sigma}{\sqrt{n}}
$$

where $\sigma$ is the standard deviation and $\mathrm{n}$ the number of simulations. Usually, an acceptable value for SEM is $1 \%$. Considering also the standard deviation value calculated using the PERT method (Table 1) for the case of the overal project duration, the minimum number of simulations can be calculated, and found to be $1,623,076$ in our case. This number of simulation is a basis for analysis, and experimenting with MCM, however, it was found that results were converging for more simulations than 70,000 . This required $<45 \mathrm{~s}$ for running the total number of simulations in a low spec PC (Intel Core Duo CPU T8100@2,10 GHz with a total of RAM 2,00GB). Indicatively, for running 1.500,000 simulations the total computational time was $11 \mathrm{~min}$ and $20 \mathrm{~s}$. Finally, it was decided, as a common reference, to run all 'experiments' with 150,000 simulations, as doubling the number of simulation above that number resulted in $<1 \%$ change in the results. The total computational time with the same computer specifications was $\sim 75 \mathrm{~s}$.

Table 1 Results of time scheduling in main scenario

\begin{tabular}{lccc}
\hline & $C P M$ & $P E R T$ & $M C M$ \\
\hline Mean duration & 591 & 601 & 598 \\
Standard deviation & - & 12.74 & 12.04 \\
\hline
\end{tabular}

Finally, the time scheduling results for the case project in the main scenario are illustrated in Table 1 (duration in days). Figure 6 presents the results for the Monte Carlo simulation in a data histogram for the early finish of the whole construction project.

In this case, PERT and MCM delivered almost the same results for the mean duration and standard deviation and as well were both of them slightly more pessimistic in the estimated duration from the deterministic CPM.

However, focusing on MCM, a number of different parameterisations of the simulation are examined in order to evaluate its effectiveness in managing the uncertainty. In particular, the effect of CI in the duration estimation, the correlation from external sources and different probability distributions were studied.

The CI is a measure of the confidence in the optimistic and pessimistic duration of each task and allows a more realistic approximation when certain reasons impose increased uncertainty in the estimation. The results for different CIs are illustrated in Table 2. 
Figure 6 Monte Carlo simulation in a data histogram for the early finish of the whole project (see online version for colours)

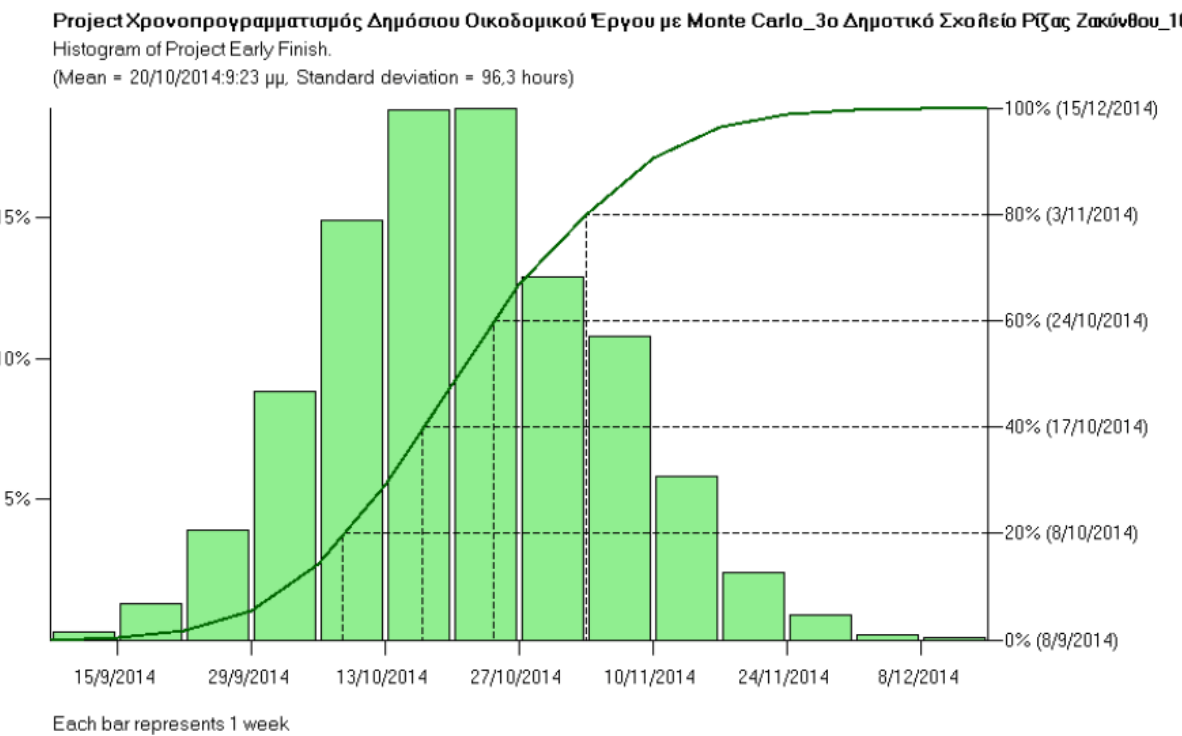

Table 2 Results of time scheduling with MCM for different CI

\begin{tabular}{lccc}
\hline & \multicolumn{3}{c}{ Confidence interval } \\
\cline { 2 - 4 } & $90 \%$ & $95 \%$ & $99 \%$ \\
\hline Mean duration & 598 & 611 & 619 \\
Standard deviation & 12.04 & 22.50 & 30.88 \\
\hline
\end{tabular}

One other aspect of Full Monte is the ability to specify correlation not only between the duration of various tasks, but also to correlate each task with outside factors which affect its duration and are called 'correlation sources'. This is achieved by introducing the $\mathrm{CC}$ that measures the degree of interdependence to this source in terms of a percentage between $-100 \%$ and $100 \%$ (for positive or negative correlation, respectively). For example, such a source is the weather conditions for tasks that are implemented outdoors. Applying this correlation source the results of the simulation are illustrated in Table 3.

Table 3 Results of time scheduling with MCM for different correlations

\begin{tabular}{lcc}
\hline & Without correlations & With correlations \\
\hline Mean duration & 598 & 598 \\
Standard deviation & 12.04 & 12.67 \\
\hline
\end{tabular}

The external correlation from the weather conditions did not affect the results of the time scheduling for the mean duration and the standard deviation as well. It can be assumed that in this case the three-point estimation covered effectively the potential effect from the weather conditions. 
In addition to time scheduling, a sensitivity analysis was performed with regards the effect of each task's duration on the project finish. The results are illustrated in a Tornado Chart (Figure 7) providing also the SI and the SAV of each critical task.

In this way, the most important of the possible critical tasks can be distinguished and therefore a better management of the uncertainty can be achieved, focusing on the statistically most valuable tasks for the project finish. These results for the main scenario of the MCM calculation are illustrated in Figure 8.

Figure 7 Tornado chart of sensitivity analysis for the critical tasks as delivered by Full Monte (see online version for colours)

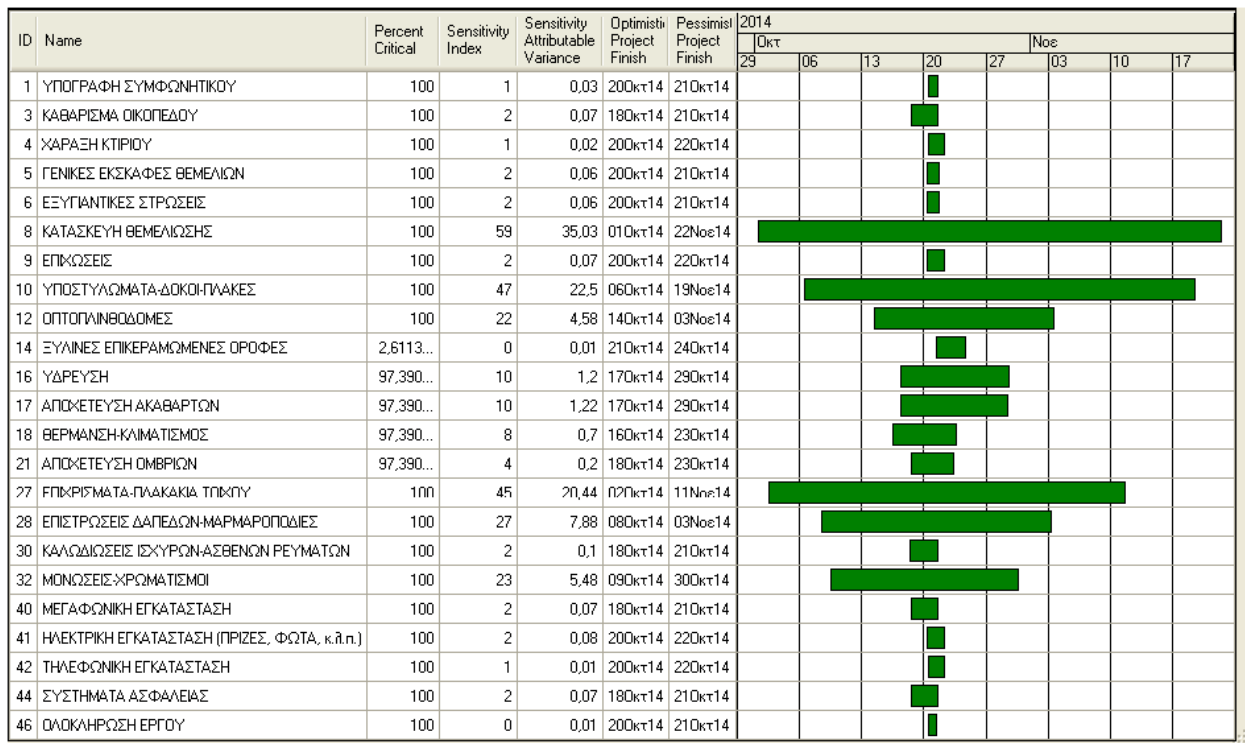

Figure 8 The relative criticality of the most critical tasks according to the sensitivity analysis (see online version for colours)

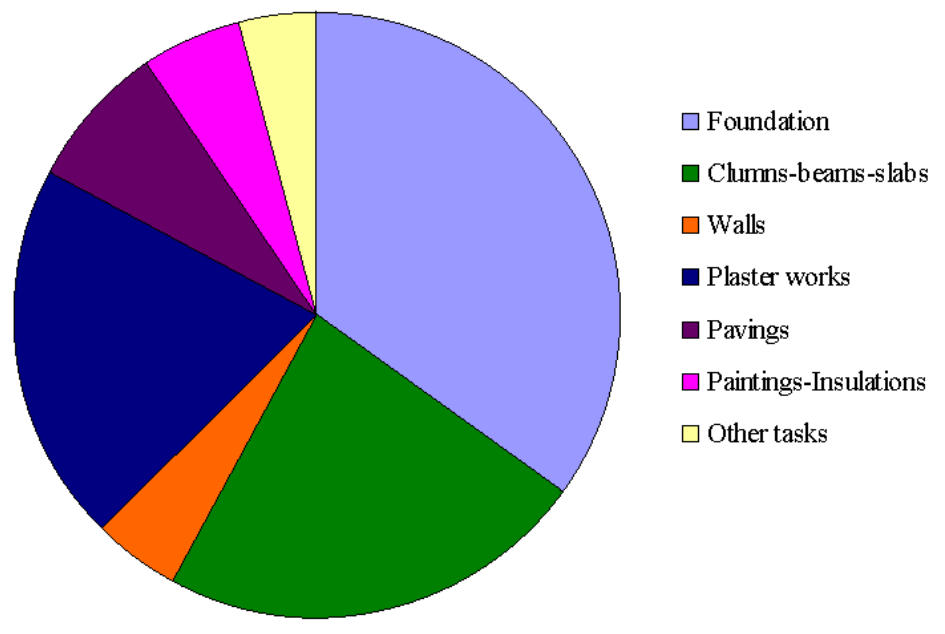


The sensitivity analysis shows that from a total amount of 22 possible critical tasks, only six concentrate the $96.41 \%$ of the total criticality in terms of SAV or even more, three of them $77.97 \%$. Similar results are obtained for the different parameterisations of the MCM simulation that are examined.

Finally, it was decided to perform a sensitivity analysis with regards the type of distribution used for each activity's duration. Besides the beta distribution, normal and triangular distributions were used for running the same MCM simulations. Table 4 summarises the results for a $\mathrm{CI}$ of $90 \%$. These results are in agreement with the findings (Golenko-Ginzburg, 1989) presented in their study.

Table 4 Results of time scheduling with MCM for different distribution types

\begin{tabular}{lccc}
\hline & \multicolumn{3}{c}{ Distribution type } \\
\cline { 2 - 4 } & Beta & Normal & Triangular \\
\hline Mean duration & 598 & 622 & 612 \\
Standard deviation & 12.04 & 12.33 & 15.50 \\
\hline
\end{tabular}

\section{Discussion of main findings}

There is a major divergence between the results of time scheduling and the real construction data. The actual duration was 715 days according to the project records and the computational duration range between 591 and 619 days maximum. It could be claimed that the most possible reason was the not accurate enough estimation of tasks time duration. By focusing on the six most critical tasks that concentrate the $96.41 \%$ of total criticality; it becomes clear that time estimations are succeeded (see Table 5) and did not cause this divergence.

Table 5 Actual duration and the three-point estimation for the most critical tasks

\begin{tabular}{lcccc}
\hline & \multicolumn{4}{c}{ Duration } \\
\cline { 2 - 5 } & Actual & $T_{o}$ & $T_{m}$ & $T_{p}$ \\
\hline Foundation & 95 & 75 & 90 & 119 \\
Columns-beams-slabs & 61 & 50 & 60 & 87 \\
Walls & 26 & 25 & 30 & 42 \\
Plaster work & 66 & 60 & 75 & 93 \\
Pavings & 62 & 50 & 60 & 70 \\
Insulations-paintings & 51 & 50 & 60 & 67 \\
\hline
\end{tabular}

A deeper examination of case project records indicated serious weaknesses in project management and application of time scheduling. In practice, the scheduled succession of the different tasks it was not followed and unjustified large time gaps occurred between them. In addition, the management was not intensive enough since no more than two different tasks were performed simultaneously, although this was feasible and was imposed by an effective time schedule. 
Therefore, the divergence that was monitored above is not due to a weakness of time scheduling procedure or a malfunction of the applied methods CPM, PERT and MCM. It indicates an extra factor of uncertainty that appeared in the case of the Greek public works. It is more of an institutional deficit rather than a classic source of uncertainty that could be quantified as a part of a calculation. Thus, it is pointed out that the managing of uncertainty in times scheduling of a public construction work in Greece is not only a matter of adoption of advanced scheduling methods. In the current situation, it mainly premises a reformation of the legal framework ruling the execution of public works, aiming at priority in their completion within deadlines.

However, apart from the above conclusion for the case-project, the current analysis demonstrated the possibility to deal effectively with uncertainty. The introduction of simulation in time scheduling is a key step in this direction. The computational capability for thousands or even millions times of simulation providing a large number of data that properly processed can significantly relieve time scheduling from uncertainty. The examination of numerous possible critical paths is also in the same positive direction. Furthermore, the new features of modern add-in software packages (e.g., Full Monte), provide the standard project management software (e.g., MS Project) with abilities to deal with uncertainty. Parameters such as CIs and external correlations provide a better modelling of time scheduling and effectively integrate various sources of uncertainty into calculations. The sensitivity analysis can also in an indirectly way assist in the management of uncertainty focusing on the statistically most valuable tasks for the project finish.

\section{Conclusions}

The implementation of MCM as a tool for managing the uncertainty in times scheduling demonstrated its strong performance and the ability to deliver reliable results. The divergence between the results of MCM and the real construction data of the case-project cannot be evaluated as a failure of the method. The large scale of this divergence proves that the real reason is something more significant than an inefficient managing of uncertainty.

The findings of the current analysis highlight a structural weakness of the framework of public works in Greece. They point out the lack of priority in time scheduling that leads to less cost-effective and in time completed projects. This is crucial because it decreases the economical efficiency of the public construction work and reduces its impact in the growth of national economy. Therefore, the necessary revisions of the national legal framework of ruling the public works should be adopted to emphasise in a stricter monitoring of its progress and in time completion. Numerous actions can be proposed in this direction. For example, the mandatory study and adoption of an integrated time schedule analysis as a part of the construction contract that will imply major economic and legal sequences for the contractor in any infringement. The placement of milestones during the construction will improve the control of project progress and will point out possible delays. The provision of economic or other bonus in the case of early completion of the project will motivate the contractor and ensure his commitment in time scheduling.

The current study also revealed the lack of a contemporary database of productivity rates for the different constructive tasks of the technical works in Greece. This would 
facilitate an objective estimation of the time duration of the individual tasks and therefore a more reliable time scheduling with less uncertainty. The development of this database inclusively for the Greek construction reality it is necessary in order to integrate the technical methods, the practices and standards followed in the country; the available materials and the climatic and geographical requirements. Such a database would also provide the possibility for a better-cost estimation of the projects, having further positive impact on the state economics.

\section{Acknowledgements}

This paper is based on the results of the postgraduate dissertation entitled "Uncertainty management of the public constructions project duration", which was developed by the authors during the academic years 2012-2013 at the Construction Management Postgraduate Program of the Hellenic Open University (HOU), Greece.

\section{References}

Adlakha, V.G. (1989) 'A classified bibliography of research on stochastic PERT networks: 1966-1987', INFOR, Vol. 27, No. 3, pp.272-296.

Anastasopoulos, P., Labi, S., Bhargava, A. and Mannering, F. (2012) 'Empirical assessment of the likelihood and duration of highway project time delays', Journal of Construction Engineering and Management, Vol. 138, No. 3, pp.390-398.

Barbecana Inc. (2012) Full Monte - User Guide, California, USA.

Braimah, N. (2013) 'Construction delay analysis techniques - a review of application issues and improvement needs', Buildings, Vol. 3, No. 3, pp.506-531

Chatzinikolaou, E. (2005) Project Management - Construction of a Building Project, Thesis, University of Piraeus, Greece.

Chrysafis, K. and Papadopoulos, B. (2014) 'Possibilistic moments for the task duration in fuzzy PERT', Journal of Management in Engineering, 10.1061/(ASCE)ME.1943-5479.0000296, 04014071

Golenko-Ginzburg, D. (1989) 'PERT assumptions revisited', Omega, Vol. 17, pp.393-396.

Gunduz, M., Nielsen, Y. and Ozdemir, M. (2013) 'Fuzzy assessment model to estimate the probability of delay in turkish construction projects', Journal of Management in Engineering, 10.1061/(ASCE)ME.1943-5479.0000261, 04014055.

Hajdu, M. and Bokor, O. (2014) 'The effects of different activity distributions on project duration in PERT networks', Procedia - Social and Behavioral Sciences, Vol. 119, pp.766-775.

Kaleem, S., Irfan, M. and Gabriel, H. (2014) Estimation of Highway Project Duration at the Planning Stage and Analysis of Risk Factors Leading to Time Overrun, T\&DI Congress 2014, pp.612-626.

Majid, M. and McCaffer, R. (1998) 'Factors of non-excusable delays that influence contractors' performance', Journal of Management in Engineering, Vol. 14, No. 3, pp.42-49.

Malcolm D.G., Roseboom J.H., Clark C.E. and Fazar, W. (1959) 'Application of a technique for research and development program evaluation', Operations Research, Vol. 7, No. 5, pp.646-669.

Maravas, A., Pantouvakis, J.P. and Lambropoulos, S. (2012) 'Modeling uncertainty during cost benefit analysis of transportation projects with the aid of fuzzy set theory', Procedia - Social and Behavioral Sciences, Vol. 48, pp.3661-3670. 
Odeh, A.M. and Battaineh, H.T. (2002) 'Causes of construction delay: traditional contracts', International Journal of Project Management, Vol. 20, pp.67-73.

PWC (2014) Funding the Future, Accessible at: http://www.pwc.com/en_GR/gr/publications/ assets/infrastructure-funding-the-future-en.pdf (accessed on 30 March, 2015).

Trietsch, D. and Baker, K.R. (2012) 'PERT 21: fitting PERT/CPM for use in the 21st century', International Journal of Project Management, Vol. 30, No. 4, pp.490-502.

Tsagkos, K. (2009) Time and Budget Schedule of a Building Construction Work with C.P.M./P.E.R.T. Methods, Thesis, University of Piraeus, Greece.

Tzintzas, Ch. (2005) The Probabilistic Approach P.E.P.T. and Monte Carlo Simulation in Project Management, Thesis, University of Piraeus, Greece.

Xiao, H. and Proverbs, D. (2002) 'Construction time performance: an evaluation of contractors from Japan, the UK and the US', Engineering, Construction and Architectural Management, Vol. 9, No. 2, pp.81-89. 